\title{
TOPOGRAPHY AND PATHOGENESIS OF LESIONS IN RHEUMATIC FEVER.
}

\author{
BY
}

\author{
A. F. BERNARD SHAW, M.D., \\ Lecturer in Pathology, University of Durham College of Medicine, \\ Newcastle-upon-Tyne.
}

In recent years interest has been revived in the pathological anatomy of rheumatic fever by the studies of MacCallum ${ }^{1}$ on lesions of the left auricle and the series of papers by Pappenheimer and Von Glahn² on lesions of the aorta and other vessels. Indeed since the description of the specific nodes in the myocardium by Aschoff (1904) and Geipel (1905), it has become increasingly apparent that the cardiac lesions are merely local manifestations of a general infection, and that the more comprehensive our anatomical studies, the more fruitful are the results likely to be.

In a girl, aged 15 years, who died in December, 1927, of rheumatic fever with chorea the autopsy revealed extensive changes, and although the microscopic lesions were recognized at that time, unavoidable circumstances prevented a detailed study of the material until recently. Only those changes which prove the generalization of the infection and those which bear upon pathogenesis are discussed, the more commonly recognized lesions being briefly dismissed.

\section{Pathological Report.}

Autopsy protocol.-Rheumatic endocarditis of mitral and aortic valves with characteristic vegetations. Mitral leaflets thickened and rigid but no stenosis. Aortic cusps slightly thickened and opaque. Dilatation and hypertrophy of heart. Organizing pericarditis. Sero-fibrinous exudate of about $500 \mathrm{c.cm}$. in right pleural cavity. Left pleural cavity obliterated by delicate adhesions. Three subcutaneous nodules each about $3.0 \mathrm{~mm}$. in size on right elbow. Chronic passive congestion of viscera.

On the cut surface of the left ventricle near its base are many opaque white points which proved to be Aschoff nodes histologically.

Of special interest are the appearances in the auricles. In the left chamber the endocardium of the posterior wall of the atrium for a distance of $3.0 \mathrm{c.cm}$. above attachment of mitral leaflet is roughened by numerous raised opaque yellowish flecks and ridges which assume a vertical direction and tend to fuse together as they approach the base of the valve where they merge with similar opacities in the sukstance of the leaflet. Similar lesions are scattered over the rest of the atrium and also in the appendix where they are vertically arranged over the musculi pectinati.

In the right auricle at the mouth of the coronary sinus and just above the attachments of the tricuspid valve are similar flecks and ridges. There are no vegetations on the thin and delicate tricuspid leaflets but beneath the endothelium are some yellowish opacities about $1.0 \mathrm{~mm}$. in length extending down to the line of closure and lying with their long axes at right angles to the free margin of the valve.

The pulmonic valve appears normal but in the base of each cusp at its attachment to the arterial ring is a continuous line of yellowish opacity extending into the cusp for about $1.0 \mathrm{~mm}$. The pulmonary artery with its main branches and the aorta throughout its whole length appear normal. 


\section{Histological Report.}

Lesions of the aorta and pulmonary artery.-Topographically the lesions involve the pulmonary artery and its two main trunks but not the branches within the lungs ; the ascending aorta, the arch, the descending thoracic but not the abdominal portion. The changes are more marked in the ascending aorta than in the other segments and less marked in the pulmonary artery than the ascending aorta. At these sites there is an inflammatory process in the adventitia and outer two-thirds of the media consisting of acute, healing, and healed lesions so dispersed that the appearances vary considerably in different parts of the same vessel. Acute lesions in the adventitia appear as infiltrations of mobile cells : lymphocytes, plasma cells, macrophages and many polymorphonuclear cells scattered diffusely through the tissue but also collected round the nutrient vessels (Fig. 1). The collagen bundles are often swollen and disintegrated and where this is so, isolated Aschoff cells are present but do not form nodes. In the nutrient vessels the endothelial cells are swollen and the walls turgid with œdema. At a later stage the polymorphonuclears have disappeared leaving the other types of mobile cells collected chiefly round the

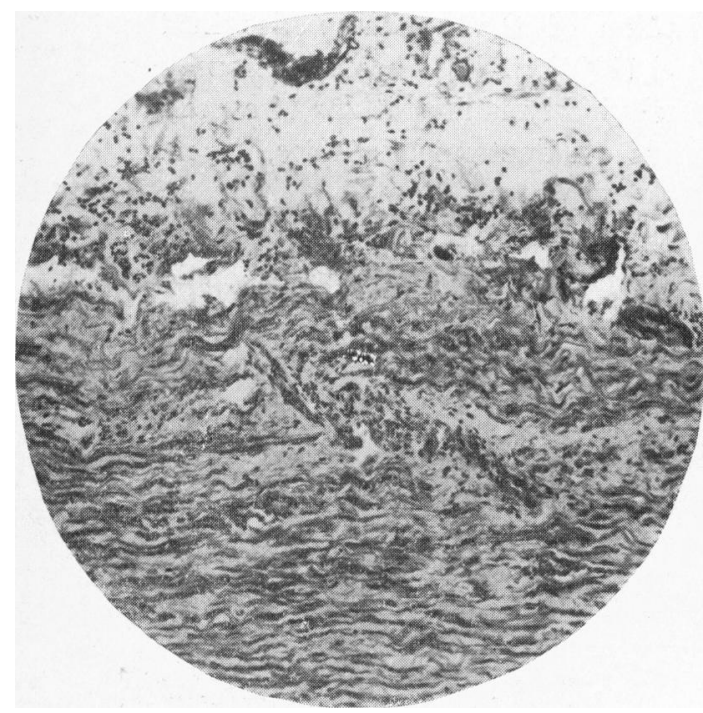

Fig. 1.-Pulmonary artery. Diffuse inflammatory cell infiltration in adventitia ; extension of the process along a nutrient vessel into the media with destruction of the muscle fibres. $\times 90$.

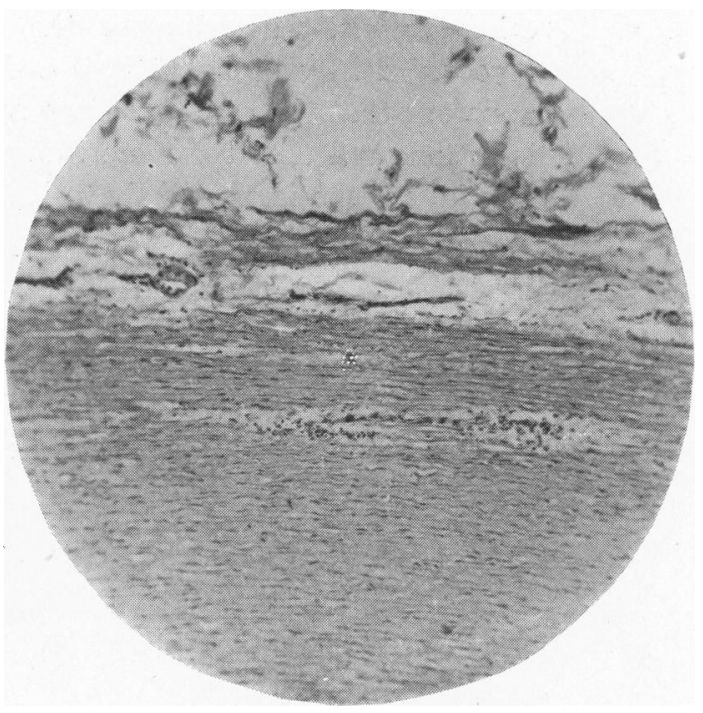

Fig. 2.-Ascending aorta. Showing proliferative endarteritis of a nutrient vessel in the adventitia and inflammatory cells round a nutrient vessel in media. $\times 40$.

nutrient vessels which are greatly thickened by proliferative endarteritis (Fig. 2). Lenticular shaped Aschoff nodes in which the large Aschoff cells lie in a matrix of swollen necrotic collagen are occasionally found in these areas (Fig. 3). Healing is effected by the formation of dense nodular scars.

The changes in the media are essentially the same but their distribution is determined by the nutrient vessels which are enveloped by inflammatory cells (Fig. 1 and 2). There is destruction of the musculo-elastic elements of the media in these foci, so that when healing occurs the thickened nutrient vessel is surrounded by a nodular scar (Fig. 4). Isolated Aschoff cells are found in the fresh lesions, but no nodes are seen in the media. In only one instance is an intimal lesion found, and this occurs in the aorta immediately above its origin from the arterial ring. Here several Aschoff cells are arranged in a single row between the lamellæ of the subendothelial tissue ; with them are some mobile cells, and cells with elongated twisted nuclei lying vertically to the surface of the aorta. As will be seen later the characters of this lesion are reproduced on a larger scale in the auricular endocardium.' 
Lesions of other vessels.-In the common carotid, subclavian and renal arteries, and superior vena cava, there is cellular infiltration of the adventitia and swelling of the nutrient vessels but the media and intima are intact. The coliac axis presents a large lenticular scar in the middle of the media with thicknening of the overlying intima and inflammatory cells round the vasa of the subjacent adventitia (Fig. 5). The splenic and the superior mesenteric arteries and a main

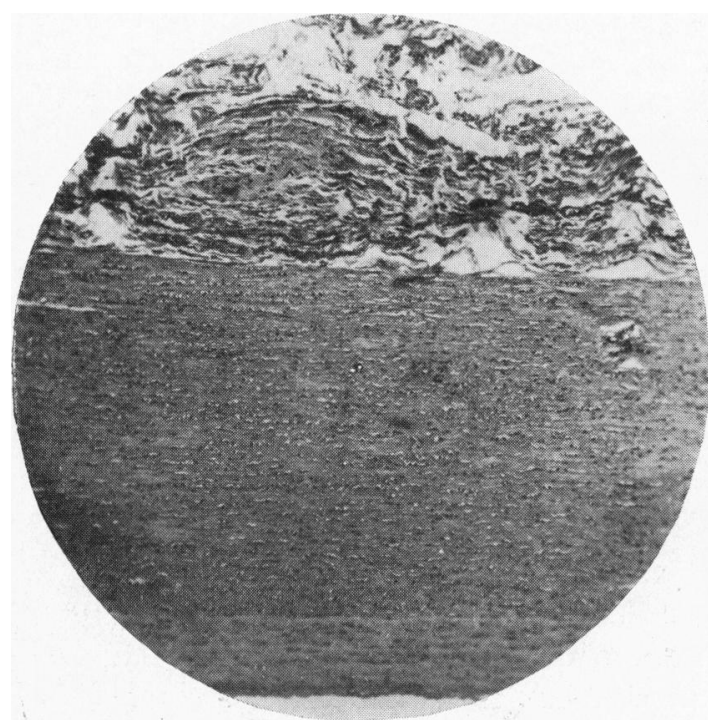

Fig. 3.-Descending thoracic aorta. Showing an Aschoff node composed of swollen collagen and large Aschoff cells lying in the adventitia. $\times 40$.

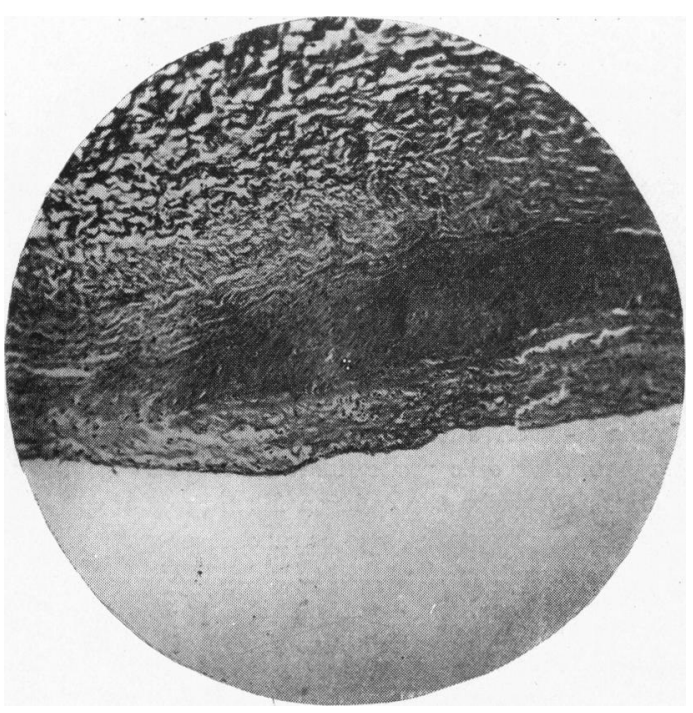

Fig. 5.-Coeliac axis. A large elliptical scar in the media is covered by thickened intima. $\times 40$.

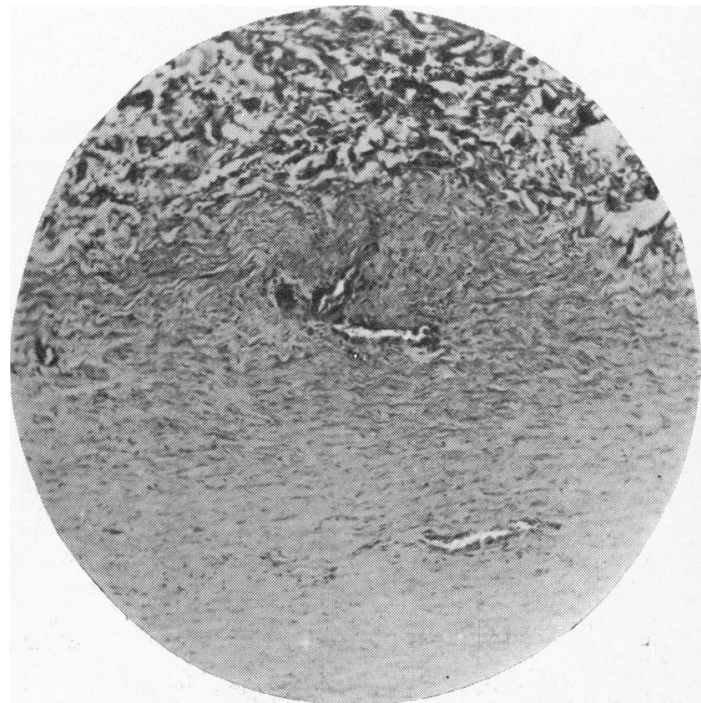

Fig. 4.-Pulmonary artery. Round a thickened nutrient vessel at junction of adventitia with media is a nodular scar. An active inflammatory focus about a nutrient vessel is seen deeper in the media. $\times 60$.

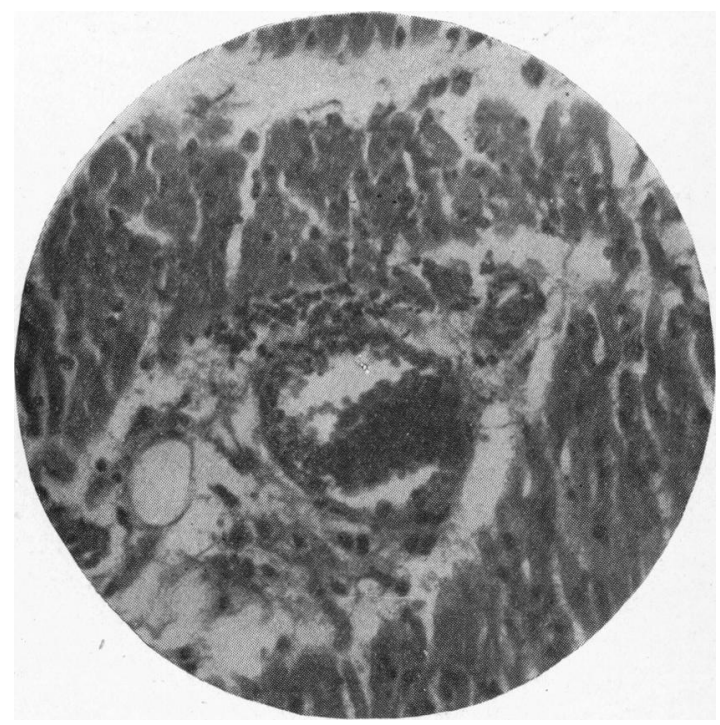

Fig. 6.-Showing a venule in wall of left ventricle. About half the circumference of the vessel is infiltrated in all its coats by polymorphonuclear leucocytes. The intima is intact and there is no thrombosis. $\times 140$. 
pulmonary vein are quite normal and no vascular or other specific lesions are found in the liver, spleen, kidneys, lungs, uterus, ovary, oviduct, pancreas, thyroid, adrenal, urinary bladder, bone-marrow and rib.

There is commonly found, however, an acute type of vascular lesion affecting venules and less frequently arterioles situated in the myocardium, atrio-ventricular sulcus, the connective tissue between the auricles and arterial trunks and the superior mediastinum. It consists of swarms of mobile cells, chiefly polymorphonuclear, which infiltrate the adventitia and extend through the necrotic media to the intima where the endothelial lining remains unbroken but is raised up like a blister over the cellular exudate (Fig. 6). Usually only a sector of the wall is involved, more rarely the whole circumference. The most striking feature of this reaction is the absence of thrombosis although specific stains reveal abundant fibrin beneath the endothelium and out. wards into the adventitia.

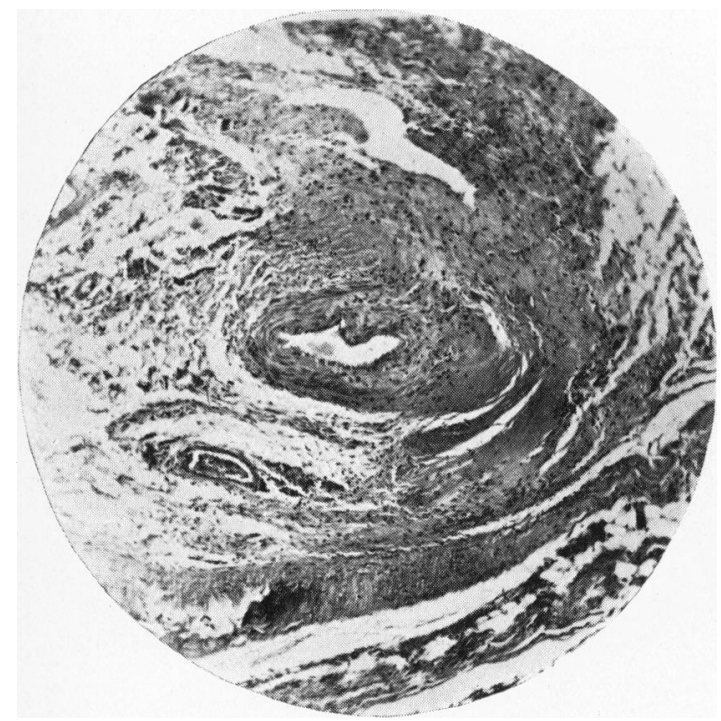

Fig. 7.-Diaphragm. Showing great scarring of the adventitia and media at one pole of an artery. Below this artery is an Aschoff node lying near a smaller vessel. $\times 60$.

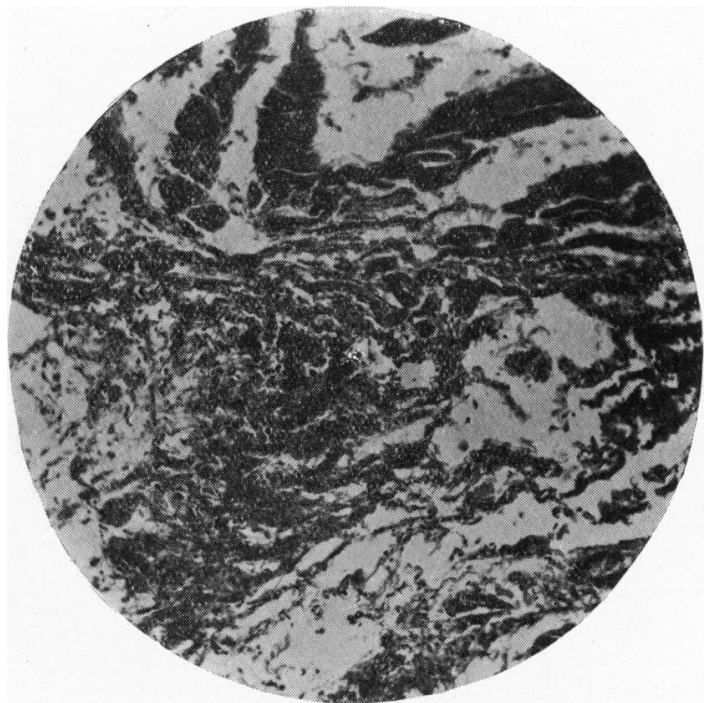

Fig. 8.-Diaphragm. A large irregularly-shared Aschoff node situated at the junction of muscle with tendon. $\times 80$.

Lesions of muscles.-The musculature of the soft palate and tongue and the hyoglossus muscle reveal no abnormality, but changes are present in the diaphragm and the superior constrictor of the pharynx where it is attached to the fibrous capsule of the tonsil. In the diaphragm the lesions present a definite relation to two structures, namely, the vessels and the connective tissue sheath which envelops the tendon bundles at their junction with the muscle fibres. A healed vascular lesion is shown in Fig. 7. where an artery is greatly thickened at one pole by dense scar tissue in the adventitia and media. Small Aschoff nodes are also found in the walls of the vessels. At the musculo-tendinous junctions in the connective tissue sheath there are either focal acute exudative lesions in which polymorphonuclear cells predominate or large Aschoff nodes of irregular outline (Fig. 8). In both forms of reaction the collagen fibres are swollen and necrotic but the tendon bundles are spared. The muscle of the superior constrictor of the pharynx is intact, but in the outer layer of the fibrous capsule of the tonsil to which the muscle fibres are attached there are a few Aschoff nodes (Fig. 9). Localizations of this kind suggest that the virus of rheumatic fever has a special affinity for the connective tissue sheath of tendon and aponeurosis, and for connective tissue to which muscle is attached. Con. firmation of this view is derived from the numerous subendothelial lesions present at the junction of the chordæ tendineæ and papillary muscles, and the marked reaction in the connective tissue 
sheath of the aponeurosis beneath the subcutaneous nodules of the elbow. In these parts too, the tendon and aponeurosis escape the injury which is located in the connective tissue envelop alone. Similarly the lesions at the insertion of the pharyngeal muscle may be compared as regards position to the annulus fibrosus of the heart which is greatly thickened by scar tissue, diffuse inflammatory infiltration and Aschoff nodes, while at the junction of the auricular and ventricular musculature with this structure Aschoff nodes are in evidence. Further, it seems probable that a topographical survey of the subcutaneous nodules in cases of rheumatic fever would show that their distribution is largely determined by this peculiarity. Of course, the specific nodes are not confined to the vicinity of tendon or aponeurosis, but wherever they occur there is always connective tissue. Indeed, the matrix of the node is always necrotic collagen which seems to constitute the initial and fundamental injury produced by the rheumatic virus, the cellular reactions being secondary. A study of numerous nodes in this case with specific

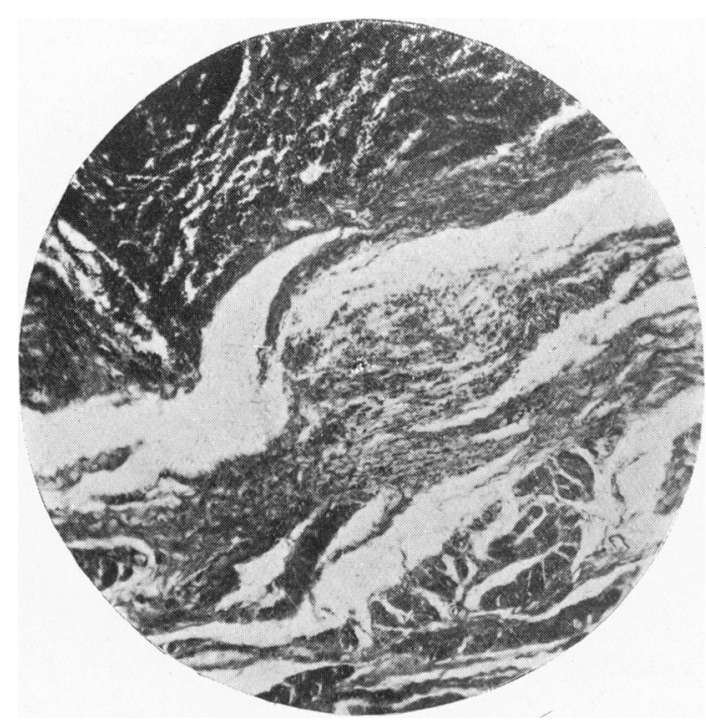

Fig 9.-An Aschoff node in the connective tissue between tonsil (above) and the superior constrictor muscle of the pharynx (below). $\times 75$.

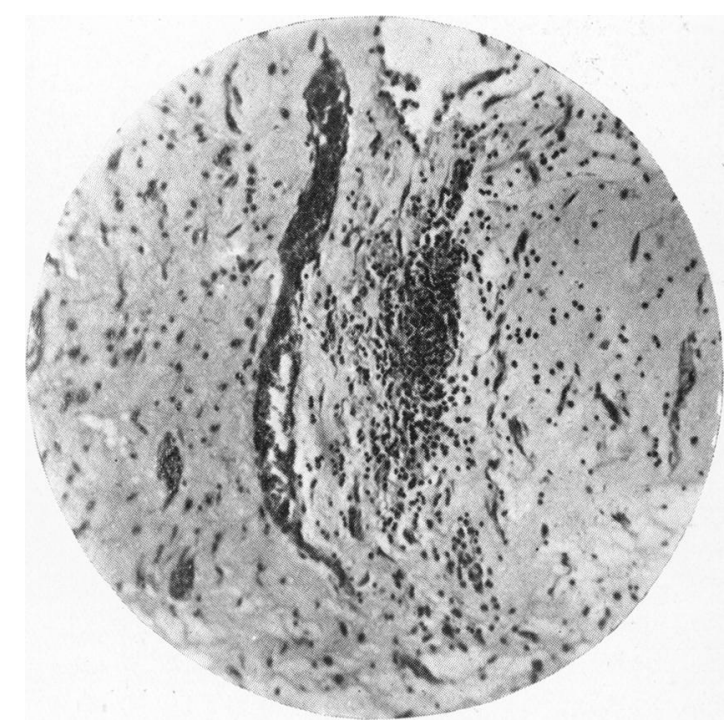

Fig. 10.-Visceral layer of pericardium. Showing an Aschoff node in the young granulation tissue of the organizing pericarditis. $\times 80$.

stains gives no support to the idea that a deposit of fibrin forms the essential basis of the reaction because this material is seldom abundant in amount and is often absent even in fresh nodes. Nor does the reaction always appear as a node; sometimes as in the auricular and ventricular endocardium, intima of aorta, visceral pericardium, the Aschoff cells are arranged in rows along bands of swollen collagen suggesting that the actual shape of the lesion depends on the texture and stratification of the affected tissue.

Lesions of serious membranes and lymphoid tissue.- In the visceral layer only of the peri. cardium there are a few characteristic nodes in the young granulation tissue (Fig. 10) and in the fibrous pericardium itself small collectiors of Aschoff cells arranged in rows along swollen collagen fibres. The right parietal pleura exhibits an organizing exudate without nodes but, curious to say, the visceral layer shows no trace of inflammation. In the lymphoid tissue (tonsil, cervical, tracheo-bronchial, mesenteric, retro-peritoneal lymph nodes, splenic lymphoid nodules) there are many plasma cells-probably a response to the demand for these cells in the lesions elsewhere; and contrary to what is found in most infective conditions in young people the germinal centres of the lymph follicles are alsent or inconspicuous. 
Brain.-No adequate anatomical basis for the chorea is found in the meninges, cerebral cortex, caudate nucleus, corpus striatum, optic thalamus, mesencephalon and pons. All these show hyperæmia but no vascular or inflammatory lesions.

Certain cardiac lesions.-Nodes are sown thickly in the walls of both ventricles, those beneath the endocardium being covered by unbroken endothelium without thrombosis on the surface. In the atrio-ventricular sulcus are many lesions in various stages of evolution : nodes where the sulcus adipose tissue joins the annulus fibrosus ; fresh and resolving nodes in and about the coronary sinus and the right and left coronary arteries. Some sections show that healing has occurred in the circumflex branches of the coronary arteries so that the intima is greatly thickened and the media deeply scarred, the appearances being like those in arterio-sclerosis. Similar changes are present in the connective tissue filling the space between the auricles, aorta and pulmonary artery. On comparing the two sides of the heart it is seen that the sulcus lesions are symmetrically arranged, and the same phenomenon comes out in other situations, namely,

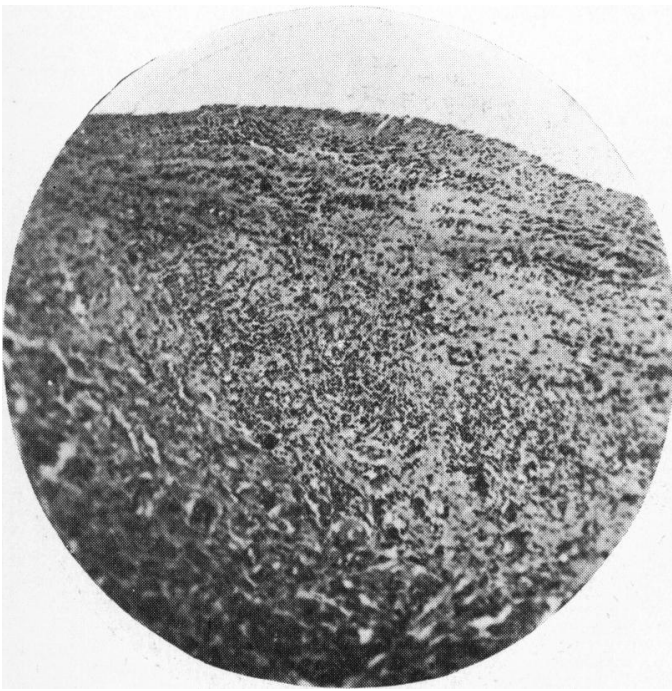

Fig. 11.-Left auricle. Showing a fairly acute lesion in the endocardium. The swollen bands of collagen are bordered by rows of large darkly stained Aschoff cells. There are many inflammatory cells near the surface and also in the outer part of the endocardium down to the muscle. Endothelium intact and no thrombi on surface. $\times 40$.

at the angle of attachment of the tricuspid and mitral valves to the annulus fibrosis and where the aortic and pulmonic valves spring from the arterial rings (Fig. 14). The changes in the auricular endocardium, more marked in the left than the right chamker, explain the gross appearances. Acute healing and healed lesions are found side by side. In the acute phase the endothelium is raised up and the subendothelial tissue inside the elastic lamina is much infiltrated with fluid and exudative cells, among which are many polymorphonuclears and cells with elongated twisted nuclei lying perpendicular to the surface. The collagen fibres inside and outside the elastic lamina are transformed into broad hyaline bands along which large Aschoff cells are arranged in rows like a palisade. The outer half of the endocardium down to the muscle is swollen with fluid and infiltrated by many wandering cells chiefly of mononuclear type (Fig. 11). There is no fibrin deposit on the surface of the unbroken endothelium. As resolution takes place the exudative cells disappear leaving the swollen collagen fibres and the Aschoff cells (Fig 12.). Healing occurs readily. Young scar tissue of delicate collagen fibrils and vertically orientated fibroblasts is formed inside the elastic lamina where it appears as a cushion-like swelling covered by intact endothelium (Fig. 13). 


\section{The Mechanism of Rheumatic Endocarditis.}

Koster (1878) appears to have been the first to suggest that endocarditis was embolic in origin rather than due to the implantation of bacteria on the surface of the valve from the passing blood. For many years his theory met with opposition owing to uncertainty regarding the presence of blood vessels in the normal valves of the adult. However in 1917 Bayne-Jones ${ }^{3}$ was able to demonstrate by injection methods a vasculature in the valves of normal hearts. He found that the mitral and tricuspid valves receive arterioles from the coronary arteries as they pass through the annulus fibrosus. These arterioles penetrate the base of the leaflet and pass downwards giving off small lateral branches which ramify in the upper third. When they reach the line of closure

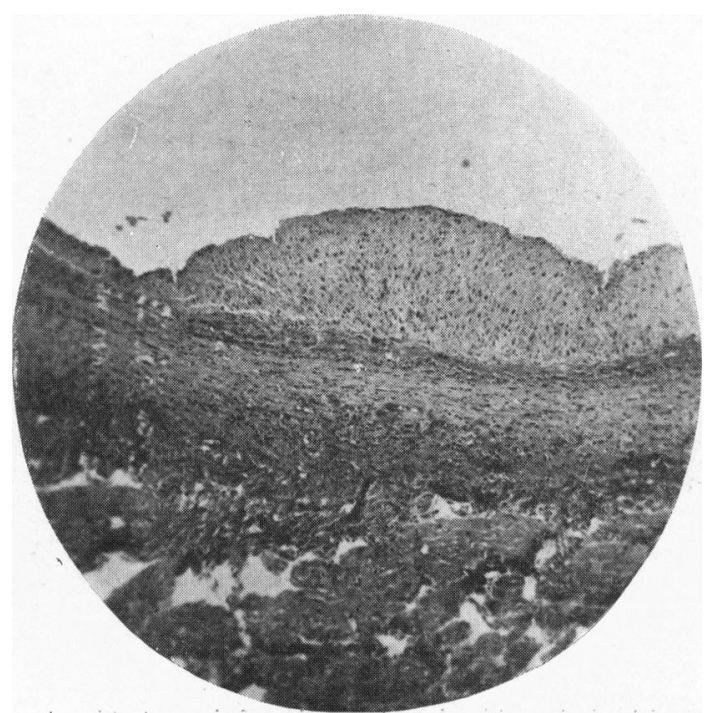

Fig. 13.--Left auricle. Representing a healed endocardial lesion which is seen as a cushion-like swelling of young scar tissue. This rests upon several layers of swollen collagen between which are many Aschoff cells in rows. $\times 40$.

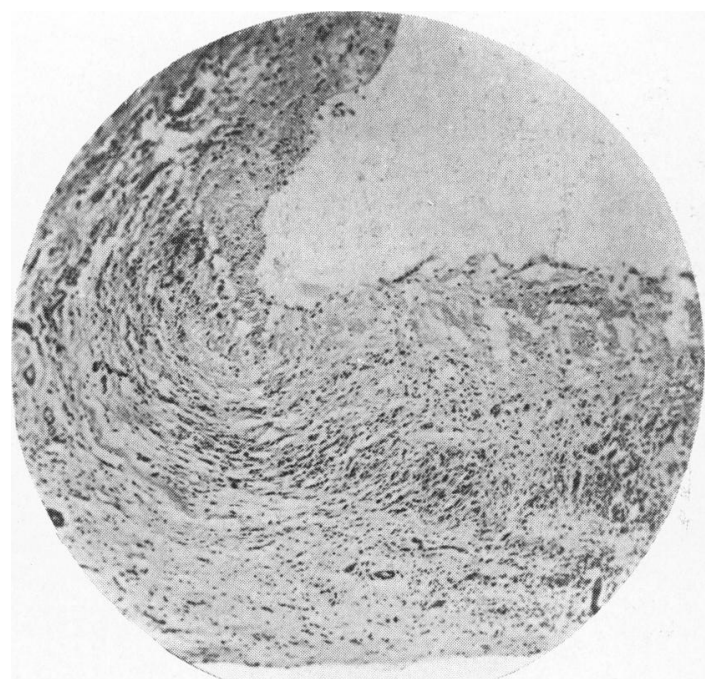

Fig. 14.- Pulmonary valve. Showing base of valve (below) at its attachment to the arterial ring (above). At the angle so formed is a small Aschoff node beneath the endo. thelium. The base of the valve is the site of an inflammatory reaction, Aschoff nodes and new-formed vessels. $\times 40$.

they undergo multiple branchings forming tufts of vessels in this region with an abundant capillary anastomosis. Only occasional strands pass from the line of closure into the filamentous edge of the valve. He also found that delicate strands of vessels pass up along the chordæ tendineæ almost to their insertion into the valve, but he failed to detect an anastomosis between these vessels and those in the valve. However, Wearn ${ }^{4}$ in the self-perfused human heart saw the vessels in the chordæ tendineæ enter the valve.

The semilunar valves receive a blood-supply from the nutrient vessels of the pulmonary artery and the aorta and from vessels of the auricular endocardium. The few delicate vessels which arise from the nutrient vessels where the valve is attached to the wall of the artery; penetrate the valve for a very short distance along its line of closure. The auricular vessels form a hedge-like 
plexus in the base of the cusp, and from this plexus delicate vessels pass upwards for a distance of about half the cusp, the rest of the cusp being devoid of vessels.

In the light of Bayne-Jones's work the changes in the tricuspid and pulmonic valves of the present case are suggestive, because they indicate the mechanism by which endocarditis and valvulitis are produced in rheumatic fever. It is important to note that there is no endocarditis of either valve and no evidence that this condition has ever been present. In about the proximal quarter of the pulmonic valve there is a characteristic inflammatory reaction with Aschoff nodes and new-formed thickened vessels (Fig. 14) which are continuous with lesions in the arterial ring. The rest of the valve out to its edge is normal and covered by unbroken endothelium. In the tricuspid leaflets

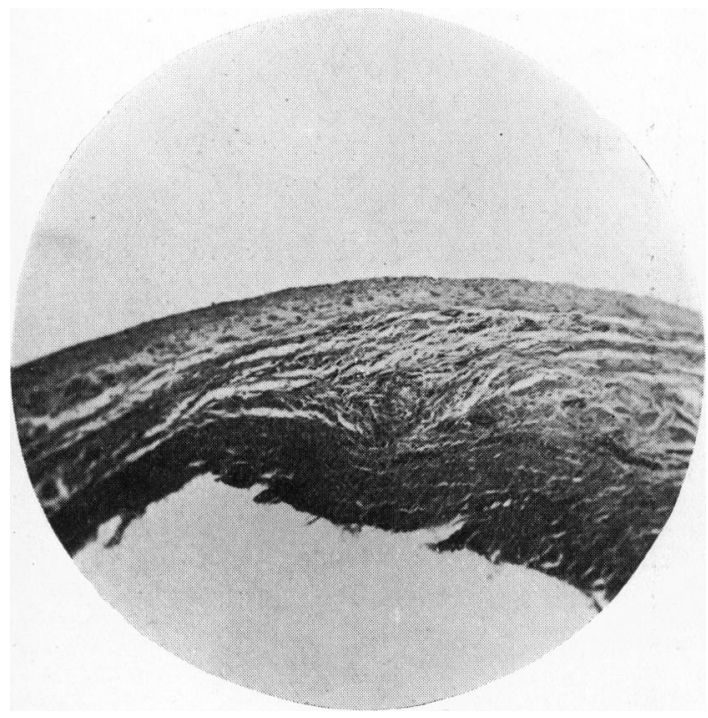

Fig. 15.-Tricuspid valve. (Proximal third). The circumscribed rounded body in centre of valve tissue is a resolving Aschoff node. A number of thickened arterioles lie to the right of the node. $\times 40$.

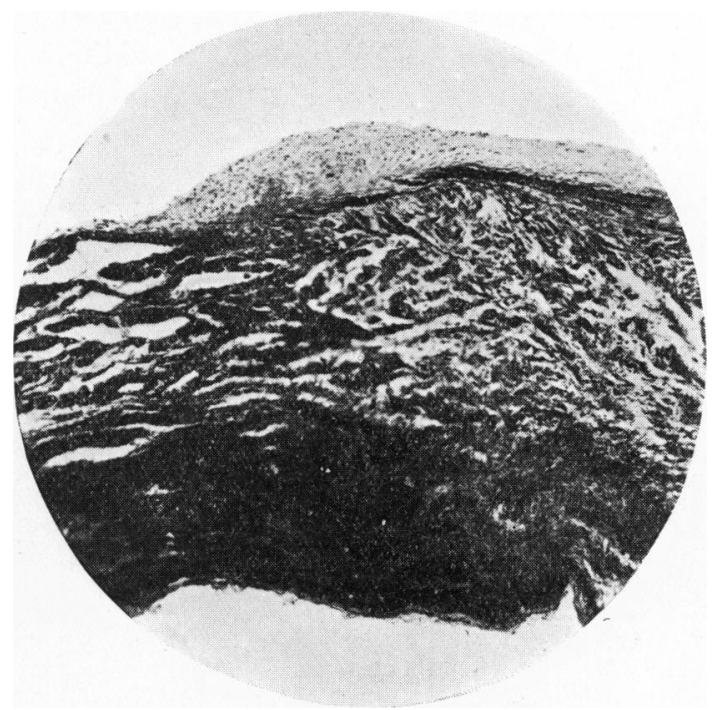

Fig. 16.-Tricuspid valve. (Near line of closure). Showing a subendothelial recent Aschoff node covered by intact endothelium. There is diffuse cellular infiltration in thickened tissueof valve. $\times 40$.

there is a diffuse valvulitis, acute healing and healed lesions being present from the base to the line of closure. Compared with a normal valve the whole leaflet is thicker and of coarser texture as if from diffuse scarring. In the basal portion are many new-formed thickened arterioles (Fig. 15) and capillaries extend down to the line of closure. Deep in the substance of the proximal portion is an Aschoff node (Fig. 15) and foci of inflammatory cells are scattered as far as the line of closure. On the auricular and ventricular faces of the leaflet are subendothelial nodes (Fig. 16), one of which near the line of closure has healed, producing a cushion-like swelling similar to the healed lesions in the auricles. This entirely confirms the opinion of Coombs, Swift and others, that in rheumatic fever valvulitis rather than endocarditis is the essentia! lesion. Yet comparison of the two valves shows that the extent of the valvulitis is different; in the pulmonic only the basal part is involved, in the tricuspid 
the whole length. This difference is governed, we believe, by the degree of vascularity. In the tricuspid, diffuse permeation with the virus occurs readily owing to the good blood-supply, and the opportunities for re-infections are increased by the healing of the inflammatory process which leads to the formation of new vessels from the pre-existing ones. In the pulmonic valve the initial infection only injures the basal sector, and since the spread of inflammation into the distal non-vascular area takes place by continuity its progress must be relatively slow.

As regards endocarditis, it has always been a matter of dispute whether destruction of the endothelium is primary or subsequent to an injury of the underlying tissue. In this connection it may be said that the rheumatic virus is not readily a thrombogenic agent, as is shown by the fact that lesions immediately beneath the mural endocardium and the intima of vessels are rarely accompanied by thrombosis-a peculiarity which also impressed von Glahn and Pappenheimer in their study of vascular lesions. Yet vegetations are almost constantly found on one or more valves in rheumatic fever, showing that some other factor must be acting in conjunction with valvulitis. As is well known, endocarditis appears along the line of closure of the valve, being rarely seen elsewhere. Now the line of closure is a zone in which mechanical stress is considerable when the leaflets come into apposition and a locus minoris resistentiæ is present in this position, so that endocardivis develops here and not elsewhere on the leaflet. But while mechanical stress alone seems to determine the location of endocarditis it does not by itself explain the relative frequency of endocarditis of the different valves. If it were the sole tactor then endocarditis should involve the left heart more than the right, the mitral as often as the aortic and the tricuspid as often as the pulmonic. However, it is known that rheumatic endocarditis involves the valves in the following order of frequency-mitral, aortic, tricuspid, pulmonic. If, however, we consider the degree of vascularity of a valve as acting in conjunction with the amount of mechanical strain imposed on it, then these two factors afford a reasonable hypothesis to explain the relative frequency of endocarditis of the four valves (see Table).

TABLE.

Illustrating Factors responsible for the Relative Frequency of Endocalidis of the Different Valves in Rheumatio Fever.

\begin{tabular}{|c|c|c|c|c|c|c|c|}
\hline Valve. & & & & Mitral. & Aortic. & Tricuspid. & Pulmonic. \\
\hline $\begin{array}{l}\text { Frequency of endocarditis } \\
\text { Amount of strain } \ldots \\
\text { Amount of vasculature }\end{array}$ & $\begin{array}{l}\cdots \\
\cdots \\
\cdots\end{array}$ & $\begin{array}{l}\cdots \\
\cdots \\
\cdots\end{array}$ & $\begin{array}{l}\cdots \\
\cdots \\
\cdots\end{array}$ & $\begin{array}{c}+++ \\
++ \\
++\end{array}$ & $\begin{array}{c}+t+ \\
++ \\
+\end{array}$ & $\begin{array}{l}++ \\
+ \\
++\end{array}$ & $\begin{array}{l}+ \\
+ \\
+\end{array}$ \\
\hline
\end{tabular}

From the study of the case reported here it seems quite clear that valvulitis precedes endocarditis, and that probably the latter cannot develop until the inflammatory process has permeated the leaflet as far as the line of closure. 
That the valvulitis can be of considerable extent and severity before endocarditis occurs is shown by the tricuspid valve, in which the anatomical conditions indicate repeated infections of the valvular tissue without the production of endocarditis before death.

It would be interesting to know how often valvulitis as distinct from endocarditis occurs in rheumatic fever, because it is evident that valves without endocarditis and otherwise normal on naked eye inspection cannot be acquitted of extensive inflammation until examined by the microscope.

My thanks are due to the Newcastle-upon-Tyne and Northern Counties Medical Society for a contributory grant from its Research Fund in aid of expenses incurred in this investigation.

\section{REFERENCES.}

1. Mac('allum, Bull, Johns Hoplins Hosp, Baltimore, 1924, XXXV, 329.

2. Pappenheimer and von Glahn, J. Med. Res., 1924, XLIV, 489. Am. J. Path., Boston, 1926. ii, 1 and 15 and 235. Ibid., 1927, XVIII, 585.

3. Bayne-Jones, Am. J. Anat., Philad., 1917, XXI, 449.

4. Wearn, J. Exp. Med., N.Y., 1928, XLVII, 273. 